\title{
Beneficial effect of ubiquinol, the reduced form of coenzyme 010 , on cyclosporine nephrotoxicity
}

\author{
Akira Ishikawa, Yukio Homma \\ Department of Urology, Graduate School of Medicine, the University of Tokyo, Japan
}

\section{ABSTRACT}

Background: Cyclosporine (CyA) nephrotoxicity is partly due to some oxidative stress. Ubiquinol, the reduced form of coenzyme Q10 (rCoQ10), has recently gained attention for its anti-oxidative potential. The aim of this study is to evaluate the effect of rCoQ10 on a CyA nephrotoxic rat model.

Materials and Methods: Six-week-old male Wistar rats were divided into three groups (five animals each). Group 1 received a medium only. Group 2 received $30 \mathrm{mg} / \mathrm{kg} /$ day of CyA only. Group 3 received both the same dose of CyA and $600 \mathrm{mg} / \mathrm{kg} /$ day of $\mathrm{rCoQ} 10$. CyA and $\mathrm{rCoQ} 10$ were both given orally for four weeks. Systolic blood pressure (BP), daily urinary albumin secretion (u-Alb), serum creatinine (s-Cr) level, and super-oxide anion (SO) level in the renal tissue were measured and compared among those three groups. Immunohistochemistry using an antibody for the transforming growth factor-beta (TGF-beta) was also examined.

Results: BPs, u-Albs, s-Crs, and SO levels of groups 1, 2, and 3 were $114 \pm 3$, $132 \pm 4$, and $129 \pm 5 \mathrm{mmHg}, 2.6 \pm 0.5,42.1 \pm 7.2$, and $22.8 \pm 3.4 \mathrm{micro}-\mathrm{g} / \mathrm{day}$ $1.1 \pm 0.2,1.7 \pm 0.2$, and $1.3 \pm 0.2 \mathrm{mg} / \mathrm{dl}$, and $224 \pm 84,1251 \pm 138$, and $512 \pm$ $109 \mathrm{RLU} / \mathrm{g}$ kidney respectively. U-Albs, s-Crs, and SO levels were significantly ameliorated by rCoQ10. Micro-vacuolar changes and TGF-beta positive deposits in the proximal renal tubular cells of CyA group rats disappeared in those of CyA and $\mathrm{rCoQ} 10$ group rats.

Conclusion: RCoQ10, an antioxidants, may have potential for preventing CyA nephrotoxicity.

\section{ARTICLE INFO}

\section{Key words:}

oxidative stress; antioxidants; cyclosporine; transforming growth factor-beta

Int Braz J Urol. 2012; 38: 230-4

Submitted for publication:

May 12, 2011

Accepted after revision: August 12, 2011

\section{INTRODUCTION}

Cyclosporine (CyA), a potent immunosuppressant, has a nephrotoxic side effect. Decrease of glomerular filtration rate caused by renal arteriolar spasms and renal interstitial fibrosis induced by transforming growth factor-beta (TGFbeta) upregulation, two major characteristics of CyA nephrotoxicity, are both evoked by some CyA-derived oxidative stress $(1,2)$. Therefore, it is expected that antioxidants have benefits against the nephrotoxic side effects of CyA. Recently, ubiquinol, the reduced form of coenzyme Q10 ( $r C o Q 10)$, a dietary supplement, has gained attention for its anti-oxidative potential (3). The following animal study was carried out to evaluate the effect of rCoQ10 on CyA nephrotoxicity.

\section{MATERIALS AND METHODS}

Animals were handled in an accredited facility according to the institutional guidelines for 
animal care and the research protocols conformed to the principles outlined by the ethical committee for animal study in the University of Tokyo.

Six-week-old male Wistar rats were divided into three groups (five animals each). Group 1 received a medium (i.e. olive oil) only. Group 2 received $30 \mathrm{mg} / \mathrm{kg} /$ day (i.e. experimentally nephrotoxic dose (4)) of CyA only. Group 3 received both the same dose of CyA and $600 \mathrm{mg} / \mathrm{kg} /$ day of rCoQ10 (Kaneka, Osaka, Japan). CyA was dissolved in olive oil at a concentration of $20 \mathrm{mg} / \mathrm{ml}$ and given orally once a day using a gastric tube. RCoQ10 was mixed with standard chow at a rate of $0.6 \%$ and fed to each rat. Both were given for four weeks.

Systolic blood pressure (BP) of each rat was monitored every week using a tail-cuff method (BP-98A, Softron, Tokyo, Japan). Twentyfour-hour urine of each rat was collected using metabolic cages on the last day and urinary albumin excretion (u-Alb) was measured by an enzyme-linked immunosorbent assay (AKRAL-120, Shibayagi, Gunma, Japan). On the last day, blood sample was obtained from each rat and serum creatinine (s-Cr) level was measured by traditional Jaffe's method using alkaline picrate (5). Whole blood CyA (WB-CyA) level was also examined by the fluorescence polarization immunoassay method. Superoxide anion levels in the whole kidney were checked by a lucigenin chemiluminescence method as previously reported (6).

Immunohistochemistry of the kidney using TGF-beta antibody (sc-146, Santa Cruz Biotechnology Inc., Santa Cruz, California, U.S.A.) was also performed.
Statistical analyses were done using ANOVA and subsequently Fisher's PLSD test. The data are presented as mean \pm SEM.

\section{RESULTS}

In 6-week-old male Wistar rats, $30 \mathrm{mg} / \mathrm{kg} /$ day of CyA for 4 weeks increased BP compared with control $(113.6 \pm 2.6$ vs. $132.4 \pm 3.8 \mathrm{mmHg}, \mathrm{p}$ $<0.001)$. U-Alb was elevated with CyA administration $(2.6 \pm 0.5$ vs. $42.1 \pm 7.2$ micro-g/day, $\mathrm{p}<$ $0.001)$ and s-Cr was also increased by CyA $(1.1 \pm$ 0.2 vs. $1.7 \pm 0.2 \mathrm{mg} / \mathrm{dl}, \mathrm{p}<0.001)$. RCoQ 10 could not ameliorate hypertension $(129.2 \pm 4.6 \mathrm{mmHg}$, NS vs. CyA group); however, it could improve albuminuria $(22.8 \pm 3.4$ micro-g/day, $\mathrm{p}<0.001$ vs. CyA group) and s-Cr elevation $(1.3 \pm 0.2 \mathrm{mg} / \mathrm{dl}$, $\mathrm{p}<0.01$ vs. CyA group, Table-1). No significant difference was seen between WB-CyA levels of groups 2 and $3(528 \pm 94$ vs. $498 \pm 85 \mathrm{ng} / \mathrm{ml})$.

Although CyA administration enhanced renal oxidative stress in 6-week-old male Wistar rats $(224 \pm 84$ vs. $1251 \pm 138$ RLU/g kidney, $p<$ 0.0001), rCoQ10 diminished S0 generation from kidney $(512 \pm 109$ RLU/g kidney, $\mathrm{p}<0.0001$ vs. CyA group, Table-1).

Micro-vacuolar changes and TGF-beta positive deposits observed in the proximal tubular cells of CyA group both disappeared by rCoQ10 administration (Figure-1).

\section{DISCUSSION}

In the present study, we demonstrated that $\mathrm{rCoQ10}$, ubiquinol, ameliorated albuminuria

Table 1 - Changes of systolic blood pressure (BP), daily urinary albumin excretion (u-Alb), serum creatinine (s-Cr) level, super-oxide anion (SO) level in the kidney.

\begin{tabular}{lllll}
\hline & $\begin{array}{l}\text { BP } \\
(\mathrm{mmHg})\end{array}$ & $\begin{array}{l}\text { u-Alb } \\
(\text { micro-g/day })\end{array}$ & $\begin{array}{l}\mathrm{s}-\mathrm{Cr} \\
(\mathrm{mg} / \mathrm{dl})\end{array}$ & $\begin{array}{l}\text { SO } \\
(\mathrm{RLU} / \mathrm{g} \text { kidney })\end{array}$ \\
\hline Control $(\mathrm{n}=5)$ & $113.6 \pm 2.6$ & $2.6 \pm 0.5^{* *}$ & $1.1 \pm 0.2$ & $224 \pm 84$ \\
CyA $(\mathrm{n}=5)$ & $132.4 \pm 3.8^{*}$ & $42.1 \pm 7.2^{* *}$ & $1.7 \pm 0.2^{*}$ & $1251 \pm 138^{\varsigma}$ \\
$\operatorname{CyA}+\operatorname{CoQ}(n=5)$ & $129.2 \pm 4.6^{*}$ & $22.8 \pm 3.4^{* *}$ & $1.3 \pm 0.2^{*}$ & $512 \pm 109^{\circledR}$ \\
\hline
\end{tabular}

${ }^{*} P<0.001$ vs. Control; ${ }^{* *} p<0.001$ with each other; ${ }^{*} p<0.01$ vs. CyA; ${ }^{\$} p<0.0001$ vs. Control \& CyA + Co $Q ;{ }^{\circledR} p<0.002$ vs. Control 
Figure 1 - Immunohistochemistry Renal tissue stained with a TGF-beta antibody (sc-146, Santa Cruz Biotechnology Inc., Santa Cruz, California, U.S.A).

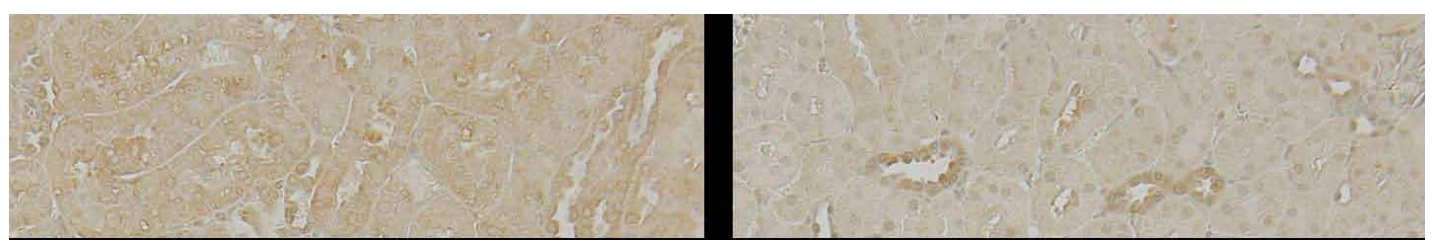

Left: Group 2: Micro-vacuolar changes and TGF-beta positive deposits are observed in the proximal tubules; Right: Group 3: Both of them are not observed.

and s-Cr elevation associated with the reduction of oxidative stress upregulation in the kidneys of 6-week-old male and CyA-loaded Wister rats. RCoQ10 also diminished TGF-beta expression in the proximal renal tubular cells.

There are several animal and clinical studies suggesting that antioxidative agents have some preventive effect of CyA nephrotoxicity (712). In 2004, Dlugosz et al reported the benefit of CoQ10 on renal transplant recipients for the first time (13); however, they used ubiquinone, the oxidized form of CoQ10. Thus, the novelty of our present study is that we could demonstrate the apparent beneficial effects of ubiquinol, the reduced form of CoQ10, with its anti-oxidative potential on CyA nephrotoxic rat model. Actually, there are two forms of CoQ10, the oxidized (ubiquinone) and the reduced (ubiquinol). Both can be taken orally with few side effects (3). Ubiquinone is changed to ubiquinol when it reachs lymphatics through small intestine (14). As a result, more than a half of total CoQ10 in the body is the reduced form in many human tissues (15). Orally administered ubiquinol significantly increases the amount of the reduced form of CoQ10 (16).

Antihypertensive effect of CoQ10 (including ubiquinol) is still controversial $(15,17,18)$. For example, Mori et al reported that ubiquinone, the oxidized form of CoQ10, showed no independent effect on blood pressure and could not reduce urinary protein in patients with chronic renal disease (17). In our present study with rCoQ10, no significant reduction of BP was observed. Our previous animal study revealed that CyA induced hypertension might be introduced by the acti- vation of intrarenal renin-angiotensin axis (4). Therefore, reno-protection by $\mathrm{rCoQ} 10$ would be accomplished through another route. Antihypertensive treatment itself is essential for the complete control of CyA nephrotoxicity.

TGF-beta is known as one of chemical mediators for tissue fibrosis $(19,20)$. Renal interstitial fibrosis is the irreversible histological damage observed in some long-term CyA-treated renal allografts (21). RCoQ10 might have potential to prevent chronic renal injury and improve the long-term outcome of renal transplantation by diminishing TGF-beta expression.

Since there was no significant difference between WB-CyA levels of groups 2 and 3, rCoQ10 might have had no interaction with CyA.

In conclusion, we demonstrated some beneficial effect of rCoQ10 against CyA nephrotoxicity probably due to its antioxidant action.

\section{ABBREVIATIONS}

CyA: cyclosporine

rCoQ10: reduced form of coenzyme Q10

BP: systolic blood pressure

u-Alb: daily urinary albumin secretion

s-Cr: serum creatinine

WB-CyA: whole blood cyclosporine

SO: super-oxide anion,

TGF-beta: transforming growth factor-beta

\section{CONFLICT OF INTEREST}

None declared. 


\section{REFERENCES}

1. Calo L, Giacon B, Davis PA, Pagnin E, Piccin A, Riegler $P$ et al:: Oxidative stress and TGFbeta in kidney-transplanted patients with cyclosporin-induced hypertension. Effect of carvedilol and nifedipine. Clin Nephrol. 2002; 58: $103-10$.

2. Rezzani R: Exploring cyclosporine A-side effects and the protective role-played by antioxidants: the morphological and immunohistochemical studies. Histol Histopathol. 2006; 21: 301-16.

3. Littarru GP, Tiano L: Bioenergetic and antioxidant properties of coenzyme Q10: recent developments. Mol Biotechnol. 2007; 37: 31-7.

4. Ishikawa A, Fujita K, Suzuki K: The influence of temocapril, an angiotensin converting enzyme inhibitor, on the cyclosporine-induced nephrotoxicity. J Urol. 1997; 157: 739-42.

5. Slot C: Plasma creatinine determination. A new and specific Jaffe reaction method. Scand J Clin Lab Invest. 1965; 17: 381-7.

6. Matsui $H$, Shimosawa $T$, Uetake $Y$, Wang $H$, Ogura $S$, Kaneko $T$ et al.: Protective effect of potassium against the hypertensive cardiac dysfunction: association with reactive oxygen species reduction. Hypertension. 2006; 48: 225-31.

7. Gökçe A, Oktar S, Yönden Z, Aydin M, Ilhan S, Ozkan OV et al.: Protective effect of caffeic acid phenethyl ester on cyclosporine A-induced nephrotoxicity in rats. Ren Fail. 2009; 31: 843-7.

8. Magendiramani V, Umesalma S, Kalayarasan S, Nagendraprabhu P, Arunkumar J, Sudhandiran G: S-allylcysteine attenuates renal injury by altering the expressions of iNOS and matrix metallo proteinase-2 during cyclosporine-induced nephrotoxicity in Wistar rats. J Appl Toxicol. 2009; 29: 522-30.

9. Uz E, Bayrak O, Uz E, Kaya A, Bayrak R, Uz B et al.: Nigella sativa oil for prevention of chronic cyclosporine nephrotoxicity: an experimental model. Am J Nephrol. 2008; 28: 517-22.

10. Capasso G, Di Gennaro Cl, Della Ragione F, Manna C, Ciarcia $R$, Florio $S$ et al.: In vivo effect of the natural antioxidant hydroxytyrosol on cyclosporine nephrotoxicity in rats. Nephrol Dial Transplant. 2008; 23: 1186-95.

11. Josephine A, Amudha G, Veena CK, Preetha SP, Varalakshmi $P$ : Oxidative and nitrosative stress mediated renal cellular damage induced by cyclosporine A: role of sulphated polysaccharides. Biol Pharm Bull. 2007; 30: 1254-9.
12. Zal F, Mostafavi-Pour Z, Vessal M: Comparison of the effects of vitamin $E$ and/or quercetin in attenuating chronic cyclosporine A-induced nephrotoxicity in male rats. Clin Exp Pharmacol Physiol. 2007; 34: 720-4. Erratum in: Clin Exp Pharmacol Physiol. 2007; 34: 953.

13. Dlugosz A, Kuźniar J, Sawicka E, Marchewka Z, LembasBogaczyk J, Sajewicz W et al.: Oxidative stress and coenzyme Q10 supplementation in renal transplant recipients. Int Urol Nephrol. 2004; 36: 253-8.

14. Mohr D, Umeda Y, Redgrave TG, Stocker R: Antioxidant defenses in rat intestine and mesenteric lymph. Redox Rep. 1999; 4: 79-87.

15. Aberg F, Appelkvist EL, Dallner G, Ernster L: Distribution and redox state of ubiquinones in rat and human tissues. Arch Biochem Biophys. 1992; 295: 230-4.

16. Ishikawa A, Kawarazaki H, Ando K, Fujita M, Fujita T, Homma Y: Renal preservation effect of ubiquinol, the reduced form of coenzyme Q10. Clin Exp Nephrol. 2011; 15: 30-3.

17. Mori TA, Burke V, Puddey I, Irish A, Cowpland CA, Beilin $L$ et al.: The effects of [omega]3 fatty acids and coenzyme Q10 on blood pressure and heart rate in chronic kidney disease: a randomized controlled trial. J Hypertens. 2009; 27: 1863-72.

18. Ho MJ, Bellusci A, Wright JM: Blood pressure lowering efficacy of coenzyme Q10 for primary hypertension. Cochrane Database Syst Rev. 2009; 4: CD007435.

19. Pribylova-Hribova P, Kotsch K, Lodererova A, Viklicky O, Vitko S, Volk HD et al.: TGF-beta1 mRNA upregulation influences chronic renal allograft dysfunction. Kidney Int. 2006; 69: 1872-9.

20. Ozdemir BH, Ozdemir FN, Demirhan B, Haberal M: TGF-beta1 expression in renal allograft rejection and cyclosporine A toxicity. Transplantation. 2005; 80: 1681-5.

21. Ishikawa A, Tanaka M, Ohta N, Ozono S, Kitamura T: Prevention of interstitial fibrosis of renal allograft by angiotensin II blockade. Transplant Proc. 2006; 38: 3498-501.

Correspondence address: Dr. Akira Ishikawa Department of Urology Graduate School of Medicine, University of Tokyo 7-3-1 Hongo, Bunkyo-ku Tokyo, 113-8655, Japan Telephone: + 813 5800-8753 E-mail: ishikawaa-uro@h.u-tokyo.ac.jp 


\section{EDITORIAL COMMENT}

The evaluation of antioxidants substances is one of the most promising research lines on the 21th century. The well known harmful effects of free radicals and their involved mechanisms on oxidative stress are even more studied nowadays. The constant search for products or substances with the objectives to stop or break this depletory process has shown lots of progression, culminating on many potential active principles for future drugs to treat this kind of cell damage.
The article discusses the potential beneficial effects of ubiquinol over the oxidative stress caused by Cyclosporine, one potent imunossupressor commonly used by patients submitted to kidney transplantation. The study performed on Winstar rats has shown some beneficial of ubiquinol over the nephrotoxicity exerced by Cyclosporine. Understanding the correct mechanisms of oxidative stress on many different situations and how to combat it, may open a space for new researches for the development of drugs or medicines to help to improve the global survival of patient/graft dependent of imunossupressors.

Dr. Fabio Tadeu Ferreira Hospital Municipal Mario Gatti, Campinas Av. Prefeito Faria Lima, 340, Parque Itália Campinas, SP, 13036-220, Brazil E-mail:fabio.urologia@gmail.com 